\title{
História e Narrativa: pensando o tema a partir de Hayden White e Alfred Schütz
}

\author{
Eduardo Henrique Barbosa de Vasconcelos* \\ Fernanda Bastos Barbosa ${ }^{\dagger}$
}

\begin{abstract}
RESUMO
A partir da década de 1970 eclodiu no campo da história, perpassando outras áreas das ciências humanas, uma série de debates e discussões que abalaram importantes pilares de sustentação da historiografia ocidental. Com a influência crescente da antropologia, história da arte, filosofia, crítica e teoria literária, vários trabalhos foram publicados problematizando a intrínseca relação entre História e Literatura. Com a chamada The linguistic turn - "Virada linguística" - a linguagem e sua dimensão performativa passaram a ser um dos centros de discussão no campo historiográfico. Nesse sentido, o presente artigo tem como objetivo apresentar e discutir o pensamento de Hayden White e Alfred Schütz sobre História e Narrativa.
\end{abstract}

Palavras-chave: Hayden White. Alfred Schütz. História. Narrativa.

\section{History and Narrative: thinking the theme from Hayden White and Alfred Schütz}

\begin{abstract}
From the 1970s, a series of debates and discussions broke out in the field of history, spanning other areas of the human sciences that undermined important pillars sustaining Western historiography. With the growing influence of anthropology, art history, philosophy, criticism and literary theory, several works have been published problematizing the intrinsic relation between History and Literature. With the call The linguistic turn - the language and its performative dimension happened to be one of the centers of discussion in the historiographic field. In this sense, the present article aims to present and discuss the thinking of Hayden White and Alfred Schütz on History and Narrative.
\end{abstract}

Keywords: Hayden White. Alfred Schütz. History. Narrative.

Artigo recebido em 17 jun. 2018.

Aprovado em 7 mai. 2019.

\footnotetext{
* Doutorando em História pela Universidade Federal do Rio Grande do Sul - UFRGS. Professor Efetivo da Universidade Estadual de Goiás - UEG. E-mail: historiaueg10@gmail.com.

${ }^{\dagger}$ Doutoranda em História pela Universidade Federal de Ouro Preto - UFOP. E-mail: fernanda.ichs@yahoo.com.br.
} 
¿Qué relación hay entre una narración y los hechos que describe? Esta es una de las preguntas que han debatido muchos de los participantes en la intensa discusión interdisciplinaria sobre la narrativa en años recientes.

David Carr

Dentre as múltiplas discussões suscitadas sobre História e Literatura, uma das mais significativas é o debate acerca da continuidade ou descontinuidade entre narrativa os atos históricos. ${ }^{1}$ Pensadores como, por exemplo, Hayden White (1928-2018) indagava-se sobre "la capacidad de una narración para representar. Al indagar 'el valor de la narratividad en la representación de la realidad', él [White] parece concluir claramente que en este sentido su valor es nulo" (Carr, 1986, p. 16). O autor de Meta-história propunha uma descontinuidade entre narrativa histórica e o mundo real.

A difusão e ampliação do debate entre História, Linguagem e Literatura, feita por diversos autores que refletiam sobre o assunto gerou o que Diogo Nunes intitulou de "um malestar" em nossa área, definido nas próprias palavras de Nunes da seguinte forma:

O mal-estar provocado pela sua obra [de Hayden White] (e, sobretudo pela circulação que ela vem tendo nestes 30 anos) se deve primordialmente à negação de que a História seja uma ciência e que, assim, possa alcançar a verdade, mas que se trata ela de texto, de discurso, de narrativa (Nunes, 2010, p. 157).

Desde então historiadores e intelectuais de outras disciplinas vêm discutindo com mais intensidade essa temática. Nesse sentido, David Carr explicou as ideias defendidas pelos autores que propõem a descontinuidade acima mencionada:

Los hechos reales simplemente no se agrupan de una manera narrativa, y si se les trata como si así fuera estamos falseando la vida. Esto no solo se debe a falta de pruebas o de verosimilitud, sino a que cualquier explicación narrativa, en virtud de su misma forma, nos presentará una imagen distorsionada de los hechos que cuenta. Uno de los resultados para la teoría literaria es la idea de la ficción narrativa que enfatiza su autonomía y separación del mudo real (Carr, 1986, p. 15).

Após essa concisa apresentação, o presente artigo tem como objetivo discutir a "narración y los hechos que describe" a partir de duas perspectivas distintas: a proposta de Hayden White, suscintamente esboçadas anteriormente e, logo em seguida, apresentaremos as considerações feitas por Alfred Schütz (1899-1959) sobre o assunto em questão. 
O escopo, portanto, é discorrer sobre o impacto da teoria whiteana no campo da historiografia das décadas de 1970 e 1980 do século XX e pensar o problema da narrativa histórica a partir de uma contrapartida, presente na obra de Schütz. Para tal, inicialmente abordaremos as ideias de Hayden White e, posteriormente, as de Alfred Schütz, pensando-as como uma possibilidade às ideias propostas pelo primeiro.

\section{O impacto da teoria literária de Hayden White para o campo da História}

Ele era mais belo do que se poderia dizer com palauras, e Aschenbach sentiu dolorosamente, como tantas outras vezes, que a palaura pode apenas exaltar a beleza sensível, jamais reproduzi-la.

Thomas Mann

Hayden White foi um historiador estadunidense conhecido por suas críticas à teoria da história e historiografia. Em 1973, publicou seu famoso livro Metahistory: The Historical Imagination in Nineteenth-Century Europe [no presente artigo consultamos a versão traduzida em português: Meta-História: a invenção histórica do século XIX] (White, 1992), trabalho no qual analisou quatro escritas de perfis históricos: Jules Michelet, Leopold von Ranke, Alexis de Tocqueville e Jacob Burckhardt; e quatro obras filosóficas sobre a história: G. W. F. Hegel, Karl Marx, F. Nietzsche e Benedetto Croce (Sutermeister, 2009, p. 43-48). Nessa obra, a história da historiografia foi pensada a partir de uma teoria da narrativa. Além deste livro, em 1978 White coligiu 12 artigos de sua autoria e publicou eles no livro de livro Tropics of Discourse: Essays in Cultural Criticism [para o presente artigo lançamos mão da versão traduzida em português: Trópicos do Discurso: ensaios sobre a crítica da cultura] (White, 1994a), trabalho cujo eixo norteador foi o status da narrativa histórica.

No artigo, O texto histórico como artefato literário, presente na obra Trópicos do Discurso, White sustentou que os historiadores sempre deixaram claro o caráter fortuito da representação histórica. Como destacou o autor, eles, os historiadores (bem como os filósofos da história), sempre "observaram a natureza essencialmente provisória e contingente das representações históricas e sua suscetibilidade a uma revisão infinita dos problemas à luz de novos testemunhos ou de uma conceituação mais elaborada" (White, 1994a, p. 194).

O que pouco foi levado em consideração, segundo o autor, foi a análise da narrativa histórica enquanto um "artefato verbal", ou seja, enquanto "ficções verbais cujos conteúdos são 
tanto inventados quanto descobertos e cujas formas têm mais em comum com os seus equivalentes na literatura do que com os seus correspondentes nas ciências" (White, 1994a, p. 98). Citamos:

A moderna teoria literária ilumina todos esses problemas dirigindo a atenção para aquilo que é bastante óbvio no discurso histórico, mas não foi sistematicamente levado em consideração até muito recentemente, ou seja, o fato de que a história é antes de mais nada um artefato verbal, produto de um tipo especial de uso da linguagem. E isso sugere que, se o discurso histórico deve ser compreendido como produtor de um tipo distinto de conhecimento, ele deve antes ser analisado como uma estrutura de linguagem (White, 1994a, p. 04).

Como apresentado acima, o que White sustenta em sua produção acadêmica que os acontecimentos históricos, por si só não possuem uma narrativa. O que existe no mundo é uma sequência de acontecimentos de valor neutro que, pelos historiadores, são transformados em estórias, e essas, montadas de forma a conter uma estrutura de começo-meio-fim. Nesse sentido,

Se a série fosse simplesmente registrada na ordem em que os eventos ocorreram originalmente, supondo-se que a ordenação dos eventos na sua própria sequência temporal tivesse fornecido um tipo de explicação do motivo pelo qual eles ocorreram e de onde ocorreram, teríamos a forma pura da crônica (White, 1994a, p. 110).

A crônica, na explicação do autor de Trópicos do Discurso, é um conjunto de fatos dispostos em ordem cronológica. De acordo com Ricardo Mello, mesmo neste nível de composição, explicação e representação de um discurso histórico já existe uma escolha por parte do historiador que seria, portanto, a ordem temporal (Mello, 2008, p. 128). Para White, partindo da influência da moderna teoria literária, o discurso histórico deve ser estudado, antes, como uma "estrutura de linguagem".

Vale ressaltar que para o autor de Meta-história, a dimensão linguística no fazer historiográfico é uma questão chave a ser levada em consideração. Nesse sentido, "não há sentido imanente às sequências históricas. E porque não há, o historiador não pode alcançá-lo. O sentido que atribui à sequência é um sentido criado, é próprio ao texto, ganha vida no texto que, por isso, é um texto literário" (Costa, 2011, p. 04).

Sendo assim, a criação de uma estória a partir das crônicas é feita através de uma operação chamada "urdidura de enredo", mecanismo que, na explicação do autor de Trópicos do discurso, produz inteligibilidade aos acontecimentos históricos, transformando o que era desconhecido em familiar (tanto para o próprio historiador, quanto para uma comunidade de 
leitores). Ou seja, é a ação de urdir, dispor em ordem, tramar os fatos em determinados tipos de estruturas de enredo. Como propôs,

Os acontecimentos são convertidos em estória pela supressão ou subordinação de alguns deles e pelo realce de outros, por caracterização, repetição do motivo, variação do tom e do ponto de vista, estratégias descritivas alternativas e assim por diante - em suma, por todas as técnicas que normalmente se espera encontrar na urdidura de enredo de um romance ou de uma peça (White, 1994a, p. 100).

Segundo White, é o próprio historiador que conforma os acontecimentos históricos em uma estrutura de enredo. O modo como um evento histórico específico é configurado dependerá de como o pesquisador harmonizará a estrutura narrativa, dando corpo e sentido a ela; um conjunto de eventos por si só não possui uma forma. "Trata-se essencialmente de uma operação literária, vale dizer, criadora de ficção. E chamá-la assim não deprecia de forma alguma o status das narrativas históricas como fornecedoras de um tipo de conhecimento" (White, 1994a, p. 102).

O que o autor defendeu, portanto, é que os fatos históricos não possuem uma narrativa acabada e completa, com começo-meio-fim. "Não vivemos estórias, mesmo que confiramos sentido a nossa vida moldando-a retrospectivamente na forma de estórias" (White, 1994a, p. 106). Os acontecimentos em si apenas podem conter elementos para o historiador a criar.

Por conseguinte, o discurso histórico no entendimento do autor de Meta-história, não é um retrato da realidade, ou espelho - para usar o sentido metafórico - do que aconteceu em um período específico, nem uma resposta ao que aconteceu em determinada época. A narrativa não descreve uma realidade extrínseca à linguagem, mas sim deve ser avaliada como um "tipo especial de uso da linguagem". Entendimento esse aceito e compartilhado por Frank Rudolf Ankersmit, para quem uma história apenas mostra parte do passado, justamente por causa da estrutura linguística que perpassa o referido discurso (Ankersmit, 2012).

Além de dialogar com literatos e filósofos, White dialogou também com a história da arte, por meio da obra de Ernst Gombrich, que ao estudar aspectos da história da arte ocidental, identificou o discurso histórico interferindo no referente do qual trata, em detrimento de ser apenas uma epifania do contexto (Gombrich, 2000). Detalhando essa proposição, Diego Nunes comenta: "Ora, a crítica 'metalinguística' não questiona a existência da realidade, mas argumenta que entre o real - a referência - e suas representações, um hiato se faz presente." Na sequência, continua Nunes: "e que esse abismo entre coisas e signos faz com que qualquer 
tentativa de mensuração da realidade seja condenada ao fracasso - e dizemos, com base em Gadamer: independente do método" (Nunes, 2010, p. 164).

É importante salientar que as dimensões imaginária e fictícia destacadas por White, ao explicar a construção do discurso historiográfico, não quer dizer que os fatos históricos não ocorreram, que foram apenas inventados, ou seja, que não existiu uma realidade. Sua proposta foi justamente dar ênfase ao papel decisivo da linguagem no processo de escrita desses acontecimentos, uma vez que:

Em resumo, o discurso histórico não deveria ser considerado primordialmente como um caso especial dos "trabalhos de nossas mentes" em seus esforços para conhecer a realidade ou descrevê-la, mas antes como um tipo especial de uso da linguagem que, como a fala metafórica, a linguagem simbólica e a representação alegórica, sempre significa mais do que literalmente diz, diz algo diferente do que parece significar, e só revela algumas coisas sobre o mundo ao prego (sic) de esconder outras tantas (White, 1994b, p. 06).

Para retornarmos à epígrafe e sintetizar a primeira parte deste tópico do artigo, ao analisarmos o trecho a partir das ideias de White percebemos um dilema acerca da representação do real. No livro Morte em Veneza [Der Tod in Venedig] (1912), do escritor Thomas Mann, apresenta Gustav von Aschenbach, famoso escritor de Munique do início do século XX e fanático pela forma e beleza ideal, que decide passar um tempo em Veneza, cidade em que conhece e se apaixona por Tadzio, lindo jovem. No desenrolar da trama, vemos como é doloroso para o artista não conseguir recriar a beleza do jovem polaco. A passagem do livro nos ajuda a clarear a discussão, pois, para os autores da "Virada Linguística", dentre eles destacamos aqui White, o real não podia mais ser representado pela escrita, gerando um impasse entre as experiências e o ato de narrá-las. Como afirmou Manoel Salgado Guimarães, comparando a situação de Aschenbach com a do historiador e seu ofício,

Trata-se na verdade, para o historiador, de enfrentar a contradição inerente entre a fixidez de um trabalho de pôr algo em discurso e a própria mobilidade do vivido. O regime da escrita, como sabemos, supõe uma ordenação, uma gramática e uma sintaxe segundo as quais as experiências encontram possibilidade de serem narradas (Guimarães, 2007, p. 30-31).

Após a exposição das principais ideias de White, contidas principalmente nos livros MetaHistória e Trópicos do discurso, faz-se necessário na sequencia, explicarmos como é construído um discurso histórico. O subtópico abaixo tem por objetivo demostrar como os eventos são urdidos pelo historiador, formando, dessa maneira, a estrutura narrativa.

\section{Estrutura de enredo conforme Hayden White}


Dialogando com as categorias propostas pelo crítico literário Herman Northrop Frye, segundo Hayden White, o historiador coloca os fatos históricos em tipos específicos de estruturas de enredo. A título de ilustração, achamos interessante aclarar as propostas de White a partir de "esquemas" que nos ajudem a compreender como é construído um discurso historiográfico. Para o autor de Meta-história, o campo histórico tem suas conclusões prefiguradas por escolhas tropológicas ${ }^{2}$. Ou seja, a narrativa é estruturada pelo historiador a partir de quatro formas de representação figurativa: metáfora, metonímia, sinédoque e ironia.

De uma forma geral, na metáfora os eventos podem ser caracterizados por semelhança ou diferença com outro evento, ou seja, eles podem partilhar qualidades (concepção de analogia). A metonímia, por sua vez, significa a parte substituída pelo todo. O exemplo utilizado por White em Meta-História foi o de "Cinquenta velas" que, como sabemos, tem por significado "Cinquenta navios". "Além dessa redução do todo à parte, pode-se reduzir um fenômeno a outro ao se estabelecer uma relação de causa-efeito ou agente-ato" (Mello, 2008, p. 125).

Já na terceira, a sinédoque, "um fenômeno pode ser caracterizado usando-se a parte para simbolizar alguma qualidade que se presume, seja inerente à totalidade" (White, 1994a, p. 48). Ao contrário da metonímia, aqui é a parte que representa o todo como, por exemplo: $\mathrm{O}$ homem é um pequeno Deus. Por último, explicamos que a ironia é a figura que nega no âmbito figurado o que no sentido literal é afirmado como positivo.

Tais categorias, na análise de Lloyd Kramer constituem:

A preocupação de White com essas categorias pré-figurativas leva-o a analisar a forma das obras históricas, pois a estrutura formal de uma narrativa (sua estrutura metahistórica) determina a relevância de qualquer fato específico e a organização de qualquer relato particular (Kramer, 2001, p. 146).

Ainda em conformidade com Kramer, para White, na explicação deste sobre as estratégias narrativas prefigurativas, existem quatro modalidades de construção de um enredo: romântica, trágica, cômica, satírica; quatro formas de argumentação: formista, mecanicista, organicista, contextualista; e quatro formas de implicação ideológica: anarquista, radical, conservadora, liberal. ${ }^{3}$ Estas três formas que, em conjunto, formam uma narrativa historiográfica, dependem dos tropos literários explicados e descritos acima (metáfora, metonímia, sinédoque e ironia), fazendo com que o discurso histórico ganhe, assim, inteligibilidade e sentido. Para Ricardo Mello, o modo de elaboração de um enredo está ligado ao nível estético, pois é a forma em que as estórias serão dispostas em uma estrutura de início-meio-fim. Por sua vez, o modo de argumentação formal se encontra em um nível epistêmico, em que o objetivo do historiador é buscar explicar os ventos ocorridos. Já o modo de implicação ideológica refere-se ao nível ético, 
pois são estas implicações que vão nortear a direção de construção do discurso (Mello, 2008, p. 132-137).

Podemos perceber, pelo quadro retirado do livro Meta-História, as afinidades existentes em cada modo para a construção de uma narrativa. É importante ressaltar, como o próprio White afirmou de forma enfática, que o esquema abaixo não é hermético, podendo, por exemplo, algumas afinidades dos referidos modos sofrer variações. Como exemplificou Ricardo Mello, Jacob Burckhardt, em sua obra, empregou um modo de elaboração de enredo satírico, contendo uma argumentação contextualista e uma implicação ideológica conservadora, "quando, pelo quadro das afinidades exposto [...], era de se esperar que a implicação ideológica fosse liberal" (Mello, 2008, p. 138).

\section{Esquema I:}

\begin{tabular}{|llc}
\hline$\underline{\text { Modo de elaboração de enredo }}$ & Modo de argumentação & Modo de implicacão ideológica \\
Romanesco & Formista & Anarquista \\
Trágico & Mecanicista & Radical \\
Cômico & Organicista & Conservador \\
Satírico & Contextualiza & Liberal \\
& &
\end{tabular}

Após a descrição do conjunto de elementos que constituem uma narrativa, exemplificaremos as ideias de White com outro esquema, representado por ele em seu livro de 1973. Ao destacar uma sequência de eventos históricos de a a e, o autor ilustrou como os acontecimentos são harmonizados em uma narrativa histórica por parte do historiador, passando assim, pela chamada "urdidura de enredo". Vejamos:

\section{Esquema II:}

1. $a, b, c, d, e \ldots n$

2. $A, b, c, d, e \ldots n$

3. a, B, c, d, e...n

4. $\mathrm{a}, \mathrm{b}, \mathrm{C}, \mathrm{d}, \mathrm{e} \ldots \mathrm{n}$

5. $\mathrm{a}, \mathrm{b}, \mathrm{c}, \mathrm{D}, \mathrm{e} \ldots \mathrm{n}$ 
6. $a, b, c, d, E \ldots n$

A sequência exposta acima (número um) demonstra uma série de eventos que serão analisados pelo historiador. Como percebemos, todas as letras estão marcadas em minúsculo, o que significa o caráter neutro dos acontecimentos históricos, ou seja, a forma pela qual se estrutura um discurso historiográfico não é indicada por eles próprios. Como afirmou White, "pela própria constituição de um conjunto de eventos com vistas a criar com eles uma estória compreensível, o historiador impõe a esses eventos o significado simbólico de uma estrutura de enredo compreensível".

A partir do esquema número dois, as letras ressaltadas em maiúscula simulam o destaque dado a determinados acontecimentos em detrimento de outros, explicando-os, assim, como causa ou "como símbolos da estrutura de enredo da série considerada como uma estória de um tipo específico" (White, 1994a, p. 109). Baseando-nos na ilustração esquemática, podemos inferir, segundo White, que, por exemplo, a narrativa que destaca um evento a como fator decisivo ( $\mathrm{a}->\mathrm{A})$ tem caráter narrativo determinista, pois coloca o evento como determinante de toda a série. Caso de Karl Marx no Manifesto Comunista. Já, por exemplo, no fator decisivo E (e -> E) a série pode ser entendida como uma narrativa apocalíptica ou escatológica. Como, por exemplo, a Filosofia da História de Hegel.

As estruturas $b, c, d$, que estão no intervalo entre a história determinista e a escatológica, assumiriam, para White, formas de enredo que, influenciado pelas categorias de Frye, ele chamou de "distintamente ficcional": o romance, a comédia, a tragédia, e a sátira, todas já mencionadas no quadro acima (White, 1992). Conforme White:

As histórias, portanto, não são apenas sobre os eventos, mas também sobre o conjunto de relações possíveis que esses eventos figuram de maneira passível de demonstração. Esses conjuntos de relações, contudo, não são imanentes aos próprios eventos; existem apenas na mente do historiador que reflete sobre eles. [...]. Mais importante, porém: parece-me que eles são imanentes à própria linguagem que o historiador deve usar para descrever os eventos anteriores a uma análise científica ou a uma urdidura fictícia desses mesmos eventos (White, 1994a, p. 110-111).

Por fim, é preciso salientar que as estruturas prefigurativas das quais o historiador se vale para construir um discurso histórico podem ser inúmeras, não sendo as acima destacadas (metáfora, metonímia, sinédoque e ironia) as únicas possíveis. O que White chamou a atenção foi para o fato de que, embora possam existir inúmeras estruturas, as utilizadas na escrita da história são aquelas compartilhadas culturalmente pelos indivíduos de uma sociedade. De 
acordo com Kramer, "na verdade, seria concebível narrar qualquer acontecimento histórico através de um número enorme de diferentes enredos, mas é pelo uso de 'estratégias explicativas' familiares que a narrativa se torna plausível" (Kramer, 2001, p. 147).

Vimos até aqui que, para Hayden White, os eventos históricos não se coligam por si só de forma narrativa. O discurso não representa a realidade e, como destacado em citação anterior, os conteúdos de uma narrativa histórica são tanto "inventados" quanto "descobertos", uma vez que os acontecimentos são urdidos por meio de técnicas discursivas de caráter tropológico. Como sintetizou,

Realmente é apenas pela operação trópica, e não pela dedução lógica, que qualquer conjunto de tipos de eventos passados que gostaríamos de chamar de "históricos" pode ser (primeiro) representado como tendo a ordem de uma crônica; (segundo) transformado pelo "enredamento" numa estória com as fases identificáveis de começo, meio e fim; e (terceiro) constituído como o assunto de quaisquer argumentos formais que possam ser aduzidos para estabelecer seu "sentido" - cognitivo, ético, ou estético, conforme o caso (White, 1994b, p. 07) .

Dito isso, a segunda parte deste artigo passa agora a discutir as principais ideias de Alfred Schütz, concernente a linguagem, pois refletir sobre suas ideias podem nos ajudar em um posicionamento crítico frente às proposições defendidas por White. Após a explicação e discussão de suas obras, retomaremos as discussões feitas por David Carr em La narrativa y el mundo real: un argumento a favor de la continuidad para fechar e sintetizar a discussão final desse artigo.

\section{Narrativa e o mundo da vida (Lebenswelt ${ }^{4}$ ): uma contrapartida a partir de Alfred Schütz}

Alfred Schütz foi um filósofo e sociólogo austríaco formado em Direito pela Universidade de Viena. Em suas obras percebemos a influência da Sociologia Compreensiva de Max Weber e das ideias do fenomenológico Edmund Husserl. Em 1932 Schütz publicou seu primeiro livro intitulado Der Sinnhafte Aufbau der sozialen Welt ${ }^{5}$ e, no ano de 1939, mudou-se para os Estados Unidos onde estabeleceu contato com as teorias condutivistas de George H. Mead e as pragmatistas de Wiliam James e John Dewey. Como destacou Jochen Dreher, "una idea fundamental, siguiendo a Willian James, es que el mundo de la vida cotidiana en tanto 'realidad eminente' está gobernada por un motivo pragmático (1959 [1890]) el cual es definido como una categoría central de mundo de la vida (Reher, 2012). 
De acordo com Dreher, Schütz preocupou-se em analisar e estudar as experiências e ações dos indivíduos na vida cotidiana. Suas ideias são necessárias neste artigo, uma vez que ele se atentou, primeiramente, em pensar como é organizada a estrutura de tempo de uma ação projetada - conceitos que serão explicados detalhadamente abaixo ${ }^{6}$.

As propostas do pensador austríaco acerca da ação humana nos ajudam a nos posicionarmos criticamente frente ao debate sobre a narrativa histórica e os fatos que ela representa. Após a discussão sobre as ideias de White, veremos agora como as obras de Schütz podem ser um contraponto às propostas do primeiro. Para tanto, iniciaremos este tópico justamente com uma apresentação do funcionamento da estrutura temporal de uma ação social.

Segundo Schütz é no mundo da vida cotidiana - ou seja, mundo intersubjetivo que já está organizado antes de nosso nascimento, no qual viveram e interpretaram indivíduos que nos precederam e que, agora, está dado a nós para vivência e interpretação (realidades préconstituídas) - que os homens agem e interagem entre si:

Desde o princípio, a nossa vida cotidiana representa um mundo de cultura intersubjetivo, já que vivemos nele como homens junto com outros homens, ligados nele, realizando trabalhos em conjunto, compreendendo os outros, $e$ fazendo os outros nos compreender; mundo de cultura porque, desde o princípio, o Lebenswelt representa um universo de significados, de contextos de sentido que devemos interpretar, e de relações de sentido que criamos somente através de nossas ações nesse Lebenswelt; mundo de cultura, também; porque sempre estamos conscientes da sua historicidade, uma historicidade que nos enfrenta pela tradição e pelos costumes e que é questionável pelo fato de que todas as coisas encontradas de forma feita remetem-se às suas próprias atividades ou àquelas de um outro das quais elas são uma sedimentação (Shöder, 2006, p. 09)

É no mundo da vida que o homem age e, dessa maneira, logo perscrutamos: como, então, o indivíduo experimenta suas ações? Para responder a este problema, precisamos entender o conceito de "ação" utilizado pelo autor em seus trabalhos.

Conforme Schütz ${ }^{7}$, todo comportamento refere-se a experiências de um indivíduo dotadas de sentido. No livro Der Sinnhafte Aufbau der sozialen Welt, Schütz explicou o significado de "sentido" que, para ele, não é algo imanente às experiências contidas em nosso fluxo de consciência, mas sim o produto de uma interpretação analítica de uma experiência passada no Agora, ou seja, depois da ação realizada. É importante destacar que nem toda experiência possui sentido para o autor, como por exemplo, os reflexos fisiológicos. Ainda segundo Schütz, estas experiências não ficam retidas em nossa memória. São "experiencias esencialmente actuales, o sea que existen solo en la actualidad de ser experimentadas y no pueden ser captadas mediante una actitud reflexiva" (Schütz, 1985, p. 200). 
Ou seja, são atividades que o homem está acostumado e habituado a fazer, não envolvendo nelas referência a intenção (Shütz, 1985, p. 100). Mas, quando o comportamento possui um projeto prévio, quando ele é idealizado e planejado, caracteriza-se como uma ação. Partilhando dessa mesma ideia, Thomas Luckmann explicou o significado desse conceito:

La acción es una forma señalada de conducta, pero también una forma señalada de no-conducta. La acción es una forma señalada, porque tiene un sentido para el actor, que supera el de las experiencias corrientes. Esto no se deja atribuir a un carácter fundamental de la conducta (la no-conducta sería presumiblemente incapaz de adoptar un carácter fundamental), sino al hecho de que ésta fue proyectada por la persona. La acción es una conducta o noconducta con la intención subjetiva. Esta intención es articulada subjetivamente en forma de proyecto (Lukmann, 2008, p. 67).

Desta maneira, com base na citação acima, podemos afirmar que a ação para Schütz (bem como para Luckmann) se constitui a partir de um projeto que é preconcebido. Para o autor de A estrutura significativa do mundo social, "debemos tener presente que, por definición, la acción se basa siempre en un proyecto preconcebido, y esta referencia al proyecto precedente es lo que dota de sentido al actuar y el acto" (Schütz, 1985, p. 203). Se o indivíduo projeta uma ação latente (estabelecida no âmbito do pensamento) e tem o objetivo de cumpri-la ela pode ser denominada de ação com objetivo de "efetuação". Mas, se a ação fica apenas no âmbito do premeditar, ela pode ser caracterizada como uma mera fantasia (Lukmann, 2008, p. 86).

Diferentemente de uma "ação latente", uma "ação manifesta" está ligada ao âmbito do fazer, "o sea, acciones que se insertan en el mundo externo [mundo físico] mediante movimientos corporales" e, já têm por si próprias o propósito de serem realizadas - estas são denominadas pelo autor de execuções. Nesse sentido, Schütz escreveu:

Una ejecución es, por consiguiente, una acción en el mundo externo basada en un proyecto y caracterizada por la intención de producir el estado de cosas proyectado mediante movimientos corporales. Entre todas las formas descriptas de espontaneidad, la ejecución es la más importante para constituir la realidad del mundo de la vida cotidiana. [...] el sí-mismo alerta integra en su ejecutar, y por su intermedio, su presente, pasado y futuro en una dimensión temporal específica; se concreta como totalidad en sus actos ejecutivos, y por medio de ellos se comunica con Otros y organiza las diferentes perspectivas espaciales del mundo de la vida cotidiana (Schütz, 1985, p. 201).

Por conseguinte, faz-se necessário discorrermos sobre o funcionamento da estrutura de tempo de uma ação projetada. Partindo das ideias de John Dewey em seu livro Human Nature and Conduct (Dewey, 2002), Schütz propôs que, ao projetar uma ação, pensamo-la no campo da imaginação, ou seja, na medida em que a projeto, antecipo em minha mente seu resultado, crio uma expectativa a respeito do que está para ocorrer. Como sublinhou, "al proyectar, 
contemplo mi acto en tiempo futuro perfecto, lo pienso modo futuri exacto" (Schütz, 1985, p. 203). Vale destacar que elas são apenas projeções de ação, podendo resultar cumpridas ou não da forma pensada. Como lembrou Luckmann, "el proyecto es una anticipación (ficticia) de una situación futura [...]" (Luckmann, 2008, p. 71).

Um dos pontos fundamentais na teoria de Schütz é que todo projeto de ação é baseado em retenções que os indivíduos têm à mão, ou seja, suas experiências acumuladas. Como dito acima, Schütz também foi amplamente influenciado pela filosofia de Edmund Husserl (18591938), estudando a fundo seus trabalhos.

Considerado o pai da fenomenologia, Husserl preocupou-se com o tema da estrutura de tempo da consciência humana, explicando-a a partir das noções de "retenção" e "protenção", aclaradas em The Crisis of European Sciences and Transcendental Phenomenology $e$ Vorlesungen zur Phänomenologie des inneren Zeitbewußtseins. Como explicou Dreher, "esta perspectiva temporal que es peculiar del proyecto tiene importantes consecuencias; todos los proyectos de mis actos futuros se basan em mi conocimiento a mano en el momento de la proyección" (Dreher, 2012, p. 85).

Podemos ilustrar esta estrutura temporal da seguinte forma:

Esquema III:

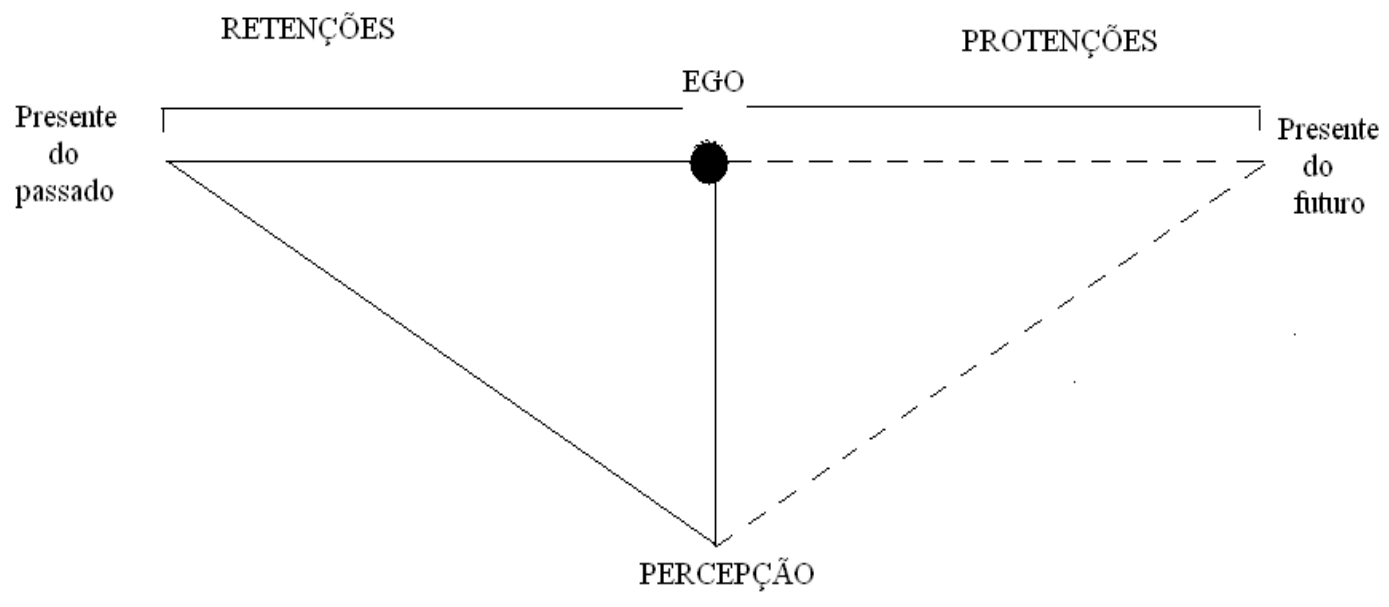

A partir do esquema acima (como também procedemos para explicar a teoria de White) procuraremos ilustrar e sintetizar a estrutura temporal de nossa consciência. 
O Ego simula no desenho o sujeito individual em seu presente imediato, presente vívido. Ou seja, onde eu me situo, o "Aqui atual", ponto de partida de minha orientação no tempo e espaço (Barco, 2012, p. 01-15). No tempo presente pertence o "mundo ao meu alcance" que, segundo Schütz, o homem experimenta como o centro de sua realidade: "mi Ahora actual es el origen de todas las perspectivas temporales por las cuales organizo los sucesos del mundo, tales como las categorías de anterior y posterior, pasado y futuro, simultaneidad y sucesión, etcétera" (Schütz, 1985, p. 209).

Compreendendo toda a dimensão do desenho, vemos que, para além do mundo que está ao meu alcance atual, existe um mundo que está ao meu "alcance potencial" que integra justamente a zona do passado, pertencente ao que "estuvo antes a mi alcance actual y lo que, según presupongo, puede ser puesto nuevamente a mi alcance actual" (presente do passado) e a zona do futuro, marcado por meus projetos e idealizações (presente do futuro)" (Schütz, 1985, p. 210) .

Ao agir no mundo o indivíduo projeta a ação a partir do "conhecimento à mão" que possui (nas palavras dos autores aqui mencionados, são as retenções). Como vemos, as retenções, marcadas em linha cheia, são minhas experiências acabadas, ou seja, uma ação que já foi feita, está finalizada, tendo sido o êxito ou fracasso de algum projeto concebido anteriormente" (Schütz, 1985, p. 203). Já as pretensões, são ilustradas em pontilhado para denotar que, mesmo sendo ações imaginadas em um futuro perfeito, elas podem ser um projeto vazio, sendo cumpridas ou não como planejadas de início.

A partir das discussões de Aron Barco, a estrutura da consciência proposta em Schütz (influenciada por Husserl) não é apresentada, por exemplo, por uma linha contínua em que, situando-me no presente, o passado é sempre algo a ser ultrapassado (ilustramos sua crítica no esquema quatro). Como argumentou, "o conteúdo que vai passando temporalmente não é um agora superado e deixado para trás, não é suplantado por uma nova vivência, mas é parte ainda do mesmo fluxo de vivência atual, como o prolongamento do ato no desenrolar de sua duração" (Barco, 2012, p. 06).

\section{Esquema IV:}

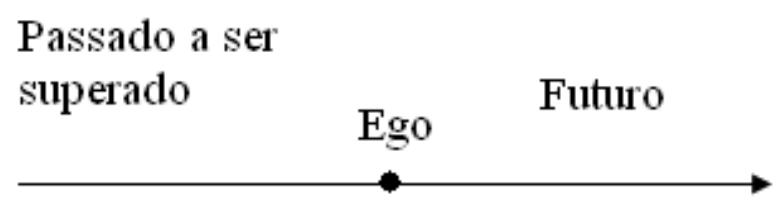


Henri Bergson e Edmund Husserl possuíram, em suas vidas intelectuais, grande preocupação em discutir sobre a consciência e o tempo interior (chamado por Bergson de durée). Para ambos, a estrutura temporal que o homem experimenta não é a mesma do mundo físico, uma vez que ela inclui a retenção de um passado, bem como a antecipação de um futuro (como vimos no esquema três). Segundo David Carr, "tal y como los hallamos, aún del modo más pasivo de nuestra parte, los eventos están cargados del significado que ellos derivan de nuestras retenciones y protensiones" (Carr, 1986, p. 16).

Portanto, entender e retomar as discussões de Alfred Schütz é de grande relevância para a reflexão aqui proposta. Compreender como o indivíduo experiencia o tempo, pensar a ação do indivíduo na vida cotidiana, aclarar como ela é marcada por projeções que são ancoradas em retenções que o homem possui em seu fluxo de consciência, é um importante ponto de discussão. Como sintetizou Luckmann:

En la elección de proyectos de acciones futuras, los seres humanos son en mayor medida libres. Pero la propia elección viene predeterminada por las experiencias anteriores acumuladas y el acervo individual de conocimiento. Obsérvese que las elecciones anteriores tienen influencia sobre las elecciones de proyectos de acción posteriores, independientemente de si las primeras elecciones correspondieron al albedrío del actor o si, por el contrario, éstas fueron impuestas socialmente; pero también independientemente de si el proyecto está orientado hacia el futuro o anclado en el pasado, determinado por rutinas (Luckmann, 2008, p. 76)

Após a exposição das principais ideias de Schütz, nas considerações finais deste artigo iremos relacionar os autores aqui discutidos mostrando como podemos nos posicionar no debate sobre narrativa histórica e o que ela representa. Para tanto, embasaremo-nos nas teses de David Carr acerca do assunto.

\section{Considerações finais}

La narrativa no es sólo una forma posiblemente exitosa de describir hechos; su estructura se inserta en los hechos mismos. Lejos de ser una distorsión formal de los hechos que relata, una explicación narrativa es prolongación de sus rasgos fundamentales. Mientras otros discuten a favor de la discontinuidad radical entre narrativa y realidad, yo no 
sólo sostendré que hay continuidad sino una comunidad formal.

Podemos, a título de conclusão e síntese da discussão, voltar à pergunta de David Carr exposta em epígrafe no início deste artigo: “¿Qué relación hay entre una narración y los hechos que describe?". Assunto tão debatido por historiadores e outros escritores da área das humanidades e que parece ainda estar longe de enfraquecer.

Como vimos, nas discussões que tratamos de Hayden White, os eventos históricos não se organizam na forma de uma narrativa, sendo, assim, "ficção narrativa" separada do mundo real. Como afirmou, "as histórias conseguem parte do seu efeito explicativo graças ao êxito em criar estórias de simples crônicas; e as estórias, por sua vez, são criadas das crônicas graças a uma operação que chamei, em outro lugar, de 'urdidura de enredo'” (White, 1994a, p. 100). Para o autor, a questão da linguagem é o ponto central a ser considerado pelo historiador.

Já a partir das propostas de Schütz (das quais Carr compartilha) podemos inferir que, para ele, a narrativa descreve os fatos históricos, estando sua estrutura inserida nos próprios fatos. Ou seja, uma explicação narrativa sobre um acontecimento passado não inventa os fatos, sendo, ao contrário, a extensão dos mesmos. Escreveu Carr: "lo que digo es que la estructura medios-y-fines de la acción despliega [desdobra] algunos de los rasgos de la estructura principiomedio-fin que la idea de la discontinuidad dice que está ausente de la vida real" (Carr, 1986, p. 19).

O argumento que Carr sustenta para afirmar tal tese (valendo-se de Husserl e Schütz, entre outros) é que, para ele, os autores - como White - que defendem a descontinuidade possuem uma noção de realidade que tem o sentido do mundo físico, ou seja, "que se supone que debe ser casual y azaroso, o que, alterna y contradictoriamente, debe estar ordenado rigurosamente sobre líneas casuales; pero en cualquier caso se supone que sea indiferente por completo a las preocupaciones humanas" (Carr, 1986, p. 17-18).

Para os fenomenólogos citados acima, o que devemos nos atentar é que não podemos considerar uma realidade primeiramente externa, física, mas sim "humana". A realidade humana seria apenas uma sequência de eventos, uma ordem sequencial como na crônica de White? (para maiores detalhes, rever o esquema dois anteriormente apresentado) - a partir deste problema/questionamento Carr propõe pensarmos nossa experiência do passar do tempo que articula uma projeção ancorada em uma retenção (esquema três). "Tal y como los hallamos, aún del modo más pasivo de nuestra parte, los eventos están cargados del significado que ellos derivan de nuestras retenciones y protensiones" (Carr, 1986, p. 18). Como o próprio Schütz 
discutiu, no limite somos seres finitos, ou seja, sabemos que um dia morreremos e, tememos isto. Esta experiência é denominada por ele de "ansiedade fundamental", a qual é a primeira antecipação de ação das que irão derivar todas as outras. Ou seja, o esforço interpretativo, a hermenêutica, é cotidiano em nossa vida.

De la ansiedad fundamental surgen los muchos sistemas interrelacionados de esperanzas y temores, deseos y satisfaciones, probabilidades y riesgos que incitan al hombre en actitud natural a tratar de dominar el mundo, a superar obstáculos, a esbozar y cumplir proyectos (Schütz, 1985, p. 214).

Relembrando o esquema número dois de White, em que os eventos estão expostos em sequência cronológica, sendo, posteriormente, transformados em estórias pelo historiador, a postura de Carr é distinta. Como defendeu, a própria narrativa é, antes de tudo, prática. Este processo narrativo prático, que ele denomina de "primeira ordem", pode até ser transformado em uma narrativa de segunda ordem, estudada pelo historiador. Mas, para ele, como vimos em citação acima, a própria vida real já possui uma estrutura de meio e fim. Como argumentou,

En este sentido, la actividad narrativa a la que me refiero es práctica antes de su conversión cognitiva o estética en la historia o en la ficción. También podemos llamarla ética o moral en el sentido amplio que usa Alasdair MacIntyre y que se deriva finalmente de Aristóteles. Esto significa que la narración en nuestro sentido es constitutiva no sólo de la acción y de la experiencia sino también del yo que actúa y experimenta (Schütz, 1985, p. 214).

Além do posicionamento de Carr, podemos mencionar a explicação de Lloyd Kramer. Ao discutir a crítica direcionada à White, Kramer mencionou que, quando White enfatiza o papel da linguagem no fazer historiográfico, parece-nos que a compreensão da história é transformada apenas em projeções dos historiadores (Kramer, 2001). Além disto, as propostas de White também parecem reduzir "a complexidade do pensamento histórico a poucos tropos discursivos" (Nunes, 2010, p. 159).

Dessa forma, acreditamos que trazer para a discussão as ideias de Alfred Schütz, contrastando-as com as ideias dos escritores da chamada Virada Linguística (com ênfase especial no trabalho do historiador Hayden White), a partir de um entendimento sobre a estrutura de tempo de uma ação projetada (tanto em um âmbito individual, quanto social), contribui para o melhor entendimento desse debate.

\section{Referências}


ANKERSMIT, Frank Rudolf. A Escrita da História: a natureza da representação histórica. Londrina, PR: EdUEL, 2012.

BARCO, Aron Pilotto. A descrição do agora em Husserl. Revista Inquietude, Goiânia, vol. 3, n.1, 2012, p. 0115. Disponível em: http://www.inquietude.org/index.php/revista/article/view/128/129. Acesso em: 12/11/17.

CARR, David. La narrativa y el mundo real: un argumento a favor de la continuidad. Revista Histórias, México, n.14, jul.-set. 1986, p. 15-28.

COSTA, Lorena Lopes da. Apontamentos de um debate contemporâneo: literatura e história. Anais do XXVI Simpósio Nacional de História - ANPUH, São Paulo, julho 2011, Disponível em: http://www.snh2011.anpuh.org/resources/anais/14/1300662053 ARQUIVO Trabalho-Teoriadahistoria-

Anpuh.pdf. Acesso em 08/11/17

DEWEY, John. Human nature and conduct: an introduction to social psychology. New York: Prometheus Books, 2002.

DREHER, Jochen. Fenomenología: Alfred Schütz y Thomas Luckmann. In: TOLEDO, Enrique de la Garza; LEYVA, Gustavo (eds.). Tratado de metodología de las ciencias sociales. México: Universidad Autónoma Metropolitana y Fondo de Cultura Económica, 2012. Disponível em: http://docencia.izt.uam.mx/egt/Cursos/MetodologiaMaestria/Drecher.pdf. Acesso em 20/11/2017.

GUIMARÃES, Manoel Luiz Salgado. O presente do passado: as artes de Clio em tempos de memória. In: ABREU, Martha; SOIHET, Rachel; GONTIJO, Rebeca (orgs.). Cultura politica e leituras do passado: historiografia e ensino de História. Rio de Janeiro: Civilização Brasileira, 2007.

GOMBRICH, Ernest Hans Josef. A História da Arte. Rio de Janeiro: LTC, 2000.

KRAMER, Lloyd. Literatura, crítica e imaginação histórica: o desafio literário de Hayden White e Dominick LaCapra. In: HUNT, Lynn (org.). A nova história cultural. São Paulo: Martins Fontes, 2001.

LUCKMANN, Thomas. Acción individual y conocimiento social. In: Conocimiento y sociedaa. Madrid: Trotta, 2008.

MELLO, Ricardo Marques de. Teoria do discurso historiográfico de Hayden White: uma introdução. Revista Opisis, Goiânia, GO, vol. 8, n. 11, 2008, p. 120-145. Disponível em http://revistas.ufg.br/index.php/Opsis/article/view/9357/6449\#.UKL-MGfgHy4. Acesso em 10/11/17. 
NUNES, Diego Cesar. História, Linguagem e Literatura: dilemas e perspectivas da historiografia contemporânea. Revista Crítica Histórica, Maceió, AL, ano I, n.2, Dezembro 2010. Disponível em http://www.revista.ufal.br/criticahistorica/attachments/article/71/HISTORIA,\%20LINGUAGEM\%20E\%20LI TERATURA rev tchuk.pdf. Acesso em 01/11/17. (NUNES, 2010)

SCHÜTZ, Alfred. Sobre las realidades múltiples. In: Human agency and language. Cambridge: Cambridge University Press, 1985.

SHÖDER, Ulrike Agathe. O conceito sócio-filosófico de Alfredo Schütz e suas implicações epistemológicas para o campo da Comunicação. In: Significação: revista de cultura audiovisual v.33 n.26 (2006), Disponível em: http://www.revistas.usp.br/significacao/article/view/65631 Acesso em: 13/12/17.

SUTERMEISTER, Paul. A meta-história de Hayden White: uma crítica construtiva à 'ciência' histórica'. Revista Espaço Acadêmico, Maringá, PR, v.9, n.97, junho de 2009, p. 43-48. Disponível em http://www.periodicos.uem.br/ojs/index.php/EspacoAcademico/article/view/7102/4141. Acesso em 02/11/17.

WHITE, Hayden. Meta-História: a invenção histórica do século XIX. São Paulo: EDUSP, 1992.

WHITE, Hayden. Trópicos do discurso: ensaios sobre a crítica da cultura. São Paulo: EDUSP, 1994a.

WHITE, Hayden. Teoria literária e escrita da história. Estudos Históricos, Rio de Janeiro, vol. 7, n. 13, $1994 \mathrm{~b}$. Disponivel em: http://bibliotecadigital.fgv.br/ojs/index.php/reh/article/view/1978. Acesso em: 13/12/17.

\footnotetext{
${ }^{1}$ Alguns trabalhos da crítica literária e filosofia foram importantes na configuração deste debate: The linguistic turn (1967) de Richard Rorty, A escritura e a diferença (1971) de Jacques Derrida, Le Plaisir du Texte (1973) de Roland Barthes e Meta-Hystory (1973) de Hayden White.

${ }^{2}$ Tropo relaciona-se a figuras de linguagem, utilização de uma palavra no sentido figurado.

${ }^{3}$ Devido aos limites deste artigo, não detalharemos neste texto as quatro modalidades de construção de enredo, forma de argumentação e implicação ideológica. O objetivo é apenas discutir como uma narrativa historiográfica é construída. Para maiores informações ver: (White, 1992).

${ }^{4}$ Conceito elaborado em 1936 pelo fenomenológico Edmund Husserl em seu livro A crise das ciências europeias e a fenomenologia transcendental.

${ }^{5}$ Em tradução livre para português: A estrutura significativa do mundo social. Outras obras de Schütz traduzidas do alemão para o espanhol são: Schütz, Alfred. Fenomenología del mundo social. Buenos Aires: Editorial Paidós, 1972; Schütz, Alfred y Luckmann, Thomas. Las estructuras del mundo de la vida. Buenos Aires: Amorrortu Editores, 1973 e Schütz, Alfred. El problema de la realidad social. Buenos Aires: Amorrortu Editores, 1974.

${ }^{6}$ O que chamamos de "onda Pós-estruturalista" das décadas de 1980 e 1990 pode ser pensado como uma reedição do que ocorreu em 1930 na Alemanha, em que os problemas epistemológicos se remetiam à questão da realidade. As ideias de Schütz foram uma reação a este acontecimento na época.

${ }^{7}$ É importante salientar que Thomas Luckmann (entre outros autores) partilhou de muitas das perspectivas de Schütz, além disto, Luckmann também foi amplamente influenciado pelas ideias de Edmund Husserl.
} 